\title{
EFL Learners' L1 Conceptual Transfer and Its Relation to Their Language Proficiency and Age
}

\author{
Abbas Bagherian \\ Sheikhbahaee University, Isfahan, Iran \\ E-mail: ab.bagherian1@gmail.com
}

Received: 24-06- 2012

doi:10.7575/ijalel.v.1n.4p.152
Accepted: 23-07- 2012

Published: 01-09- 2012

URL: http://dx.doi.org/10.7575/ijalel.v.1n.4p.152

\begin{abstract}
The present study was carried out to scrutinize the possibility and extent of transfer at the level of concepts in parity and internal content based on Jarvis' (2007) framework among Iranian EFL learners having the following in focus: concepts in Persian that do not have counterparts in English, concepts that are broader than a corresponding concept in English or vice versa, and concepts in Persian and English that seem to be broadly equivalent but are still different. Also, it investigated to examine the role of the two learner-based variables of language proficiency and age in Iranian EFL learners' possible conceptual transfer. To serve the purpose, the data were collected from 100 Iranian learners (70 females, 30 males) studying English as a foreign language in an English Language School in Mobarakeh, Isfahan. With the data being submitted to statistical analyses, the findings revealed significant cases of conceptual transfer from Persian to English. It was also noticed that the participants' level of English proficiency played a significant role in their transfer of concepts but their age did not.
\end{abstract}

Keywords: cross linguistic influence, Conceptual Transfer Hypothesis (CTH), conceptual errors, concept transfer, conceptualization transfer

\section{Introduction}

A survey of recent cross linguistic research demonstrates that there have been many studies on different dimensions of language such as investigations into phonetics (e.g., Flege \& MacKay, 2004), syntactic structures (e.g., Matthews and Yip, 2003), and pragmatics (e.g., Yu, 2004), all emphasizing the importance of transfer and the role of negative language influence in second and foreign language learning. Along with these studies, some scholars (e.g., Jarvis, 1998, 2007; Jarvis \& Pavlenko, 2008, Odlin, 2008) have recently attended to the language transfer at the level of concepts and have attempted to apply their inferences from recent theoretical and empirical findings to language transfer.

Jarvis (2007) introduced the term Conceptual Transfer Hypothesis (CTH) characterized as "the hypothesis that certain instances of cross linguistic influence in a person's use of one language originate from the conceptual knowledge and patterns of thought that the person has acquired as a speaker of another language" (p. 44). Although the term conceptual transfer appeared sporadically in its informal sense in studies published throughout the 1980s and 1990s (e.g., Ijaz, 1986; Kroll and Potter,1984; MacWhinney, 1992; Rocher, 1993), a new technical sense of this term and its methodological and theoretical issues were delicately proposed and discussed by Jarvis (2007). Regarding the theoretical issues, there is a classification of Concept Transfer and Conceptualization Transfer. As for methodological issues, four cross linguistic conceptual prerequisites have been suggested: 1 . Parity, 2. Internal concept, 3. Internal structure, and 4. External membership.

Given the four categories of concept transfer in $\mathrm{CTH}$, it seems that conceptual transfer may lead to conceptual errors resulting from the tendency of ESL/EFL learners to assume that concepts in the native and target languages are always identical and can be transferred without considering the possible cross linguistic conceptual differences. Traditionally, in the fields of linguistics and SLA, a good deal of research has concentrated on linguistic as well as on semantic transfer (e.g., Jiang, 2000, 2002, 2004), but few studies have treated conceptual transfer. Besides, despite the attempts made in conceptual transfer, the achievements to date have been more exploratory than thorough examination of the issues (Oldin, 2005). Thus, empirical investigations into conceptual transfer and errors could be of significant importance in language teaching, in particular with regard to foreign language 
International Journal of Applied Linguistics \& English Literature

ISSN 2200-3592 (Print), ISSN 2200-3452 (Online)

Vol. 1 No. 4; September 2012

learners considering the fact that EFL learners are not mostly living in an English language country and consequently they are not exposed to enough input and opportunity to comprehend and internalize foreign language concepts.

\subsection{Scope and objectives of the study}

The current study is an investigation which falls within Jarvis' (2007) concept and conceptualization transfer. Regarding conceptualization transfer, it considers the way the learners perceive, recall, and reason an object, event, and relationship. With respect to concept transfer, it focuses on parity and internal content, that is, concepts in L1 that do not have counterparts in L2, concepts in L1 that are simply broader than corresponding concepts in L2 or vice versa, and concepts in L1 and L2 that seem to be broadly equivalent but are still different. Also, as the role of individual variables has always been discussed and emphasized by researchers (e.g., Odlin, 1989) interested in language transfer, the present study examines the role of the two factors of foreign language proficiency and age in L2 learners' possible conceptual transfer. In short, this research aims to answer the following questions:

1. To what extent do Iranian EFL learners at elementary and intermediate levels transfer concepts from Persian to English?

2. What is the role of EFL learner's language proficiency and age in their conceptual transfer?

\section{Background}

The work by Lakoff (1987) on the nature of conceptual representations and their interaction with language, Levelt (1989) on the process of speech production, and von Stutterheim and Klein (1987) on a concept-based approach to SLA research highly succeeded in bringing conceptual transfer to the attention of researchers in the fields of SLA and bilingualism. Also, among studies in 1990s, an important attempt was Slobin's (1991) work on the thinking for speaking hypothesis (TFSH) being directly relevant to the transfer at the level of concept. However, after the work of Jarvis and Pavlenko in 1998, conceptual transfer began to become a technical term referring to research on cross linguistic influence grounded in theories and empirical findings on the nature of conceptual representations.

Odlin (2005) defines conceptual transfer in relation to Linguistic Relativity Hypothesis: “Linguistic relativity is often defined as the hypothesized influence of language on thought ... conceptual transfer can accordingly be defined as those cases of linguistic relativity involving, most typically, a second language" (p. 5). Jarvis mentions that conceptual transfer "assumes that certain types of cross linguistic effects that we find in the language behavior of language learners, bilinguals, and multilinguals, originate from influences that have taken place in the conceptual system prior to the conversion of conceptual structure into linguistic structure." (2009, p. 2).

According to Jarvis (2007) the word 'conceptual' refers to both concept and conceptualization. Jarvis (ibid) contends that concept transfer arises from "cross linguistic differences in the conceptual categories stored in L2 users' long-term memory" while conceptualization transfer arises from "cross linguistic differences in the ways L2 users process conceptual knowledge and form temporary representations in their working memory"(p. 52). He divides conceptualization transfer into three levels: (a) general, nonlinguistic cognition, (b) macroplanning for speaking, and (c) microplanning for speaking. With respect to concept transfer, he presents four prerequisites as shown in Table 1.

Table 1. Cross Linguistic Conceptual Prerequisites for Concept Transfer (Jarvis, 2007)

\begin{tabular}{ll}
\hline 1. Parity & A concept in Language A does not have a counterpart in Language B (or vice versa) \\
\hline $\begin{array}{l}\text { 2.Internal } \\
\text { Concept }\end{array}$ & $\begin{array}{l}\text { A concept in Language A does not have the same internal content as the corresponding } \\
\text { concept in Language B }\end{array}$ \\
\hline $\begin{array}{l}\text { 3.Internal } \\
\text { Structure }\end{array}$ & $\begin{array}{l}\text { A concept in Language A does not have the same internal structure as the corresponding } \\
\text { concept in Language B }\end{array}$
\end{tabular}

\begin{tabular}{ll}
\hline 4. External & A concept in Language A does not belong to the same superordinate categories as the \\
Membership & $\begin{array}{l}\text { corresponding concept in Language B, or it does not have the same status within those } \\
\text { categories }\end{array}$
\end{tabular}


Conceptual transfer should not be confused with semantic transfer. Odlin (2005) states that "All conceptual transfer involves meaning transfer but not all meaning transfer involves conceptual transfer. In effect, conceptual transfer is a subset of meaning transfer" (p. 6). In this regard, Jarvis (2007), focusing only on concept transfer, considers Finnish student's sentence (he bit himself in the language) as an example of semantic transfer and adds, "semantic transfer involves cross linguistic influence related to the links between words and concepts, but not the makeup of concepts themselves"(p. 60). In fact, he believes that concept transfer involves differences in conceptual distinctions, whereas semantic transfer is more a matter of how words are mapped onto concepts

\section{Research Method}

\subsection{Participants}

The participants of the study were 100 Iranian EFL learners (70 females, 30 males) studying English as a foreign language in an English Language School in Mobarakeh, Isfahan. All available learners were 700: 400 elementary learners ranged between the ages of 10 and 27 and 300 intermediate learners ranged between the ages of 15 and 27.

At first, all available learners were stratified by age at each level resulting in three elementary groups and two intermediate groups. Then 20 participants were selected from each of the five age groups using a random sampling method; the sampling frame was merely separate lists of all members at each group. As represented in Table 2, the selected learners at the elementary level comprised three groups of 20: one group of children (10-13), one group of teenagers (14-17), and one group of young adults (18-27). The selected learners at the intermediate level consisted of two groups of 20: one group of teenagers aged between 15 and 17 and one group of young adults aged between 18 and 27 .

Table 2. Distribution of Available Learners and Participants by Age and Proficiency

\begin{tabular}{llllll}
\hline level & \multicolumn{2}{c}{ Age groups } & Total N & \multicolumn{2}{c}{ Selected N } \\
\hline \multirow{2}{*}{ Elementary } & $10-13$ & Children & 152 & 20 \\
\cline { 2 - 5 } & $14-17$ & Teenagers & 157 & 20 & 60 \\
\cline { 2 - 5 } & $18-27$ & Young Adults & 91 & 20 & 40 \\
\hline Intermediate & $15-17$ & Teenagers & 162 & 20 & 20 \\
\cline { 2 - 5 } & $18-28$ & Young Adults & 138 & \\
\hline
\end{tabular}

\subsection{Instrument}

This study benefited from two proficiency tests and one researcher-designed questionnaire. Excerpted from Nelson English Language Tests, the two proficiency tests $050 \mathrm{~B}$ and $250 \mathrm{D}$ were administered to the elementary and intermediate learners respectively in order to make sure of their homogeneity at each level. To measure the degree of participants' conceptual transfer, a questionnaire was planned in three parts (A, B, and C), each consisting of 10 items requiring the participants to fill in the blanks based on the sentences in Persian, translate some sentences from Persian to English, and select appropriate options in 'two-choice' items. The following are three examples, each representing a sample item in the sections A, B, and C of the questionnaire respectively:

1. Please, give me a glass of . . . . . . . .

2.

3. A baker is a person who bakes and sells .......

$$
\begin{aligned}
& \text { لطفا يك ليوان آب يرتقال به من بده. } \\
& \text { دختر كلى دارى. }
\end{aligned}
$$
a. bread
b. bread, cakes, and cookies

Each item in the questionnaire was specifically designed so as to contain a concept which might be transferred from Persian to English (see the boldfaced words in the above examples). Singled out from nearly 80 cases, the 30 concepts fell into parity and internal content categories of the concept transfer classification proposed by Jarvis (2007). The following is the elaboration of the items in the questionnaire:

A. Parity:

- Concepts related to the expressions in Persian that lack an English equivalent such as [خسته نباثنيد]: [khasteh nabashid] 
International Journal of Applied Linguistics \& English Literature

ISSN 2200-3592 (Print), ISSN 2200-3452 (Online)

Vol. 1 No. 4; September 2012

- Concepts that seem to be religiously culture-specific and have no counterparts in English such as تعزيه [خواند: [ta-aziyeh khandan].

- Concepts that are culture-bound. Although we may find some English concepts that are somewhat close to them, they do not include the same internal content like [نغل آزاد]: [shoghl e azad]

B. Internal Content

- Concepts in Persian that are simply broader than their corresponding concepts in English or vice versa.

- Concepts in Persian that seem to be broader than their corresponding concepts in English such as [خوردن]: [khordan] (meaning: to eat) that is also used for drinks, medicine, etc. which is not the case in English.

- Concepts in English that seem to be broader than their corresponding concepts in Persian such as[baker] that is used for a person who bakes and sells bread, cakes, and cookies, while its Persian counterpart [نانو]: [nanva]is a person who only bakes and sells bread.

- Concepts that are metaphorically broader in Persian such as ] [ک $\mathrm{J}:$ [gol] (meaning: flower) used to compliment someone: [ختر [كل: dokhtar e [gol].

- Concepts in Persian and English that seem to be broadly equivalent but are still different in relation to which particular objects or events, etc. are included in the concept.

- Concepts that are equally broad but are different in their internal content mostly because of the differences in the two cultures like [dog] versus[سگ]: $[\mathrm{sag}]$

- Concepts that are equally broad but are metaphorically different in English and Persian such as the concept [moon] and [oL] :[mah]. The former is metaphorically used for describing a round face but the latter for describing a beautiful face.

Before administering the questionnaire, a preparatory pilot study was conducted which led to some slight changes in the selected concepts and the design of the questionnaire. For example, the participants at the elementary level were provided with the meaning of unfamiliar words in the third part of the questionnaire and a few items were omitted and replaced with new ones.

\subsection{Procedure}

First, the participants, three elementary and two intermediate groups, each consisting of 20 learners, were selected based on their age and language proficiency as described above. After that, two proficiency tests were used to be assured of the participants' homogeneity at each level. Next, a questionnaire was given to the participants to fill out. In the questionnaire, each item was marked 0 where the conceptual transfer occurred and 1 where no conceptual transfer occurred even if the learners did not provided appropriate equivalents for the concepts. Here, the focus was on the learners' awareness of differences between the concepts in the two languages.

\section{Data Analysis}

In order to examine the extent of conceptual transfer by the participants and the role of language proficiency in this transfer, the data from the questionnaires were collected and analyzed. Tables 3 and 4 are the results of the descriptive statistics and T-test respectively:

Table 3. Descriptive Statistics at Each Level and Category

\begin{tabular}{llllll}
\hline \multirow{2}{*}{ Category } & Level & $\mathrm{N}$ & Mean & Std. Deviation & Std. Error Mean \\
\hline Parity & Elementary & 60 & 2.53 & 1.171 & .151 \\
\cline { 2 - 5 } & Intermediate & 40 & 5.40 & 1.057 & .167 \\
\hline Internal Content & Elementary & 60 & 5.75 & 1.503 & .194 \\
\cline { 2 - 5 } & Intermediate & 40 & 10.73 & 2.136 & .338 \\
\hline Total & Elementary & 60 & 8.28 & 1.923 & .248 \\
\cline { 2 - 5 } & Intermediate & 40 & 16.13 & 2.430 & .384 \\
\hline
\end{tabular}


International Journal of Applied Linguistics \& English Literature

ISSN 2200-3592 (Print), ISSN 2200-3452 (Online)

Vol. 1 No. 4; September 2012

Table 4. The Results of T-Test on Two Categories of Transfer

\begin{tabular}{llcc}
\hline Categories & \multicolumn{2}{l}{ T-test for Equality of Means } & Sig. \\
\cline { 2 - 4 } & $\mathrm{T}$ & $\mathrm{Df}$ & $(2$-tailed) \\
\hline Parity & & & .001 \\
\hline Internal Content & -12.458 & 98 & .001 \\
\hline Total & -13.676 & 98 & .001 \\
\hline
\end{tabular}

As illustrated in Table 3, there was a noticeable difference between the total means of the two levels as well as their means at each category. Also, Table 4 indicates that the observed p-value was far less than the alpha decision level $(\alpha<.001)$

In order to examine the role of age in the participants' conceptual transfer, the data were analyzed separately at each level. Tables 5 and 4 are the results of the analyses at the intermediate level.

Table 5. Descriptive Statistics of the Intermediate Level at Each Category

\begin{tabular}{llllll}
\hline \multicolumn{1}{c}{ Categories } & Age Group & $\mathrm{N}$ & Mean & Std. Deviation & Std. Error Mean \\
\hline Parity & $15-17$ & 20 & 5.50 & 1.000 & .224 \\
\cline { 2 - 6 } & $18-27$ & 20 & 5.30 & 1.129 & .252 \\
\hline Internal Content & $15-17$ & 20 & 10.25 & 2.489 & .557 \\
\cline { 2 - 5 } & $18-27$ & 20 & 11.20 & 1.642 & .367 \\
\hline Total & $15-17$ & 20 & 15.75 & 2.653 & .593 \\
\hline
\end{tabular}

Table 6. The Results of T-Test of the Intermediate Level

\begin{tabular}{llll}
\hline \multirow{2}{*}{ Categories } & \multicolumn{4}{l}{ T-test for Equality of Means } \\
\cline { 2 - 4 } & $\mathrm{T}$ & $\mathrm{Df}$ & Sig. (2-tailed) \\
\hline Parity & .593 & 38 & .557 \\
\hline Internal Content & -1.425 & 38 & .162 \\
\hline Total & -.975 & 38 & .336 \\
\hline
\end{tabular}

As observed in Table 6, the total significance level (.336) was more than the alpha decision level (.05).

Tables 7 and 8 indicate the results of the role of age at the elementary level.

Table 7. The Results of ANOVA (one-way) of the Elementary Level

\begin{tabular}{lllll}
\hline Categories & & Sum of Squares & Df & Mean Square \\
\hline Parity & Between Groups & 11.033 & 2 & 5.517 \\
\cline { 2 - 5 } & Within Groups & 69.900 & 57 & 1.226 \\
\cline { 2 - 5 } Internal Content & Total & 80.933 & 59 & \\
\cline { 2 - 5 } & Between Groups & 33.700 & 2 & 16.850 \\
\cline { 2 - 5 } & Within Groups & 99.550 & 57 & 1.746 \\
\cline { 2 - 5 } Total & Total & 133.250 & 59 & 40.417 \\
\cline { 2 - 5 } & Between Groups & 80.833 & 2 & 2.410 \\
\hline
\end{tabular}


International Journal of Applied Linguistics \& English Literature

ISSN 2200-3592 (Print), ISSN 2200-3452 (Online)

Vol. 1 No. 4; September 2012

Table 7. The Results of ANOVA (one-way) of the Elementary Level

\begin{tabular}{lllll}
\hline Categories & & Sum of Squares & Df & Mean Square \\
\hline Parity & Between Groups & 11.033 & 2 & 5.517 \\
\cline { 2 - 5 } & Within Groups & 69.900 & 57 & 1.226 \\
\cline { 2 - 5 } & Total & 80.933 & 59 & \\
\hline Internal Content & Between Groups & 33.700 & 2 & 16.850 \\
\cline { 2 - 5 } & Within Groups & 99.550 & 57 & 1.746 \\
\cline { 2 - 5 } & Total & 133.250 & 59 & 40.417 \\
\hline \multirow{2}{*}{ Total } & Between Groups & 80.833 & 2 & 2.410 \\
\cline { 2 - 5 } & Within Groups & 137.350 & 57 & \\
\cline { 2 - 5 } & Total & 218.183 & 59 & \\
\hline
\end{tabular}

Table 8. The Results of ANOVA (one-way) of the Elementary Level

\begin{tabular}{llll}
\hline Categories & & F & Sig. \\
\hline Parity & Between Groups & 4.499 & .015 \\
\hline Internal Content & Between Groups & 9.648 & .001 \\
\hline Total & Between Groups & 16.773 & .001 \\
\hline
\end{tabular}

As shown in Table 7, the total observed p-value was estimated to be .001, much less than the alpha decision level $(\alpha<.001)$.

Also, the mean plots of the participants' performance indicated that the leaner-based variable of age was an important factor in the amount of transfer in the category of parity among the three elementary groups while at least two age groups were different in the category of internal content as well as for the total mean (between age groups of 10-13 and 14-17 or 18-27).

\section{Results}

This study revealed that:

1. The participants significantly transferred concepts or some of their features from Persian to English and sought to find a nonexistent, word for word translation.

2. Language proficiency of the learners affected their conceptual transfer. The elementary learners erroneously transferred concepts twice as much as the intermediate learners and relied more on their native conceptual system.

3. Age difference in the elementary learners played a role in their conceptual transfer, but not in the intermediate learners.

4. The variable of age was a significant factor in the amount of transfer in the category of parity among the three elementary groups.

5. However, in the category of internal content, it seems at least two groups were different in transferring concepts based on the age factor.

\section{Discussion}

The results of this study confirm Jarvis' (2007) idea of conceptual transfer, which assumes foreign language learners "often refer to the same objects and events in conceptually different ways and in ways that are specific to their language backgrounds" (p. 44). On the other hand, some findings of this study support Danesi's (2008) argument of conceptual errors. To be more specific, in this study, the conceptual transfer occurred in the sub-categories of metaphorically broader and equally broad but metaphorically different overlap the types of conceptual errors viewed by Danesi (2008). These types of errors might be committed when L2 learners encode meanings in the target language with identical or parallel structures of their native language.

The findings for the role of language proficiency can be discussed in relation to some views proposed on 
language and conceptual transfer in the literature. In this study, the learners at the elementary level had a higher rate of negative conceptual transfer than those at the intermediate level which is in line with other studies holding that language transfer is more likely to occur at lower levels of proficiency (Odlin, 1989 among others). Also, it is in line with the role of length and amount of language exposure and language dominance and proficiency, two of the nine key factors that Jarvis and Pavlenko (2008) believe influence the conceptual change in L2 learners. Accordingly, conceptual change may be most visible in speakers with a high amount of past and present interaction with L2 and low amount of interaction with the L1. Thus, they consider language dominance and proficiency as important factors affecting conceptual change.

The role of the language proficiency in conceptual transfer in this study can be justified through the two processes of conceptual translation and conceptual awareness. The former, suggested by Danesi (2008), occurs when L2 learners during the earliest phases of second language learning unconsciously rely on their native conceptual system (CS1) to decipher novel input and direct the choice of L2 structures; therefore, they express themselves largely through the process of conceptual translation. Similarly, it seems that in this study the learners of lower proficiency, compared to those of higher proficiency, relied more on their CS1 through the process of conceptual translation. Regarding conceptual awareness, its role in conceptual transfer parallels the effect of language awareness on language transfer. As the role of explicit knowledge and conscious monitoring in decreasing the occurrence of transfer (e.g. Odlin, 1989; Jarvis, 2002) or in avoiding negative transfer (e.g. Kasper, 1997) has constantly been highlighted, this role can likewise be discussed at the level of concepts. To be more specific, the extent to which L2 learners are aware of the possible differences in concepts between the L1 and L2 may be considered as their conceptual awareness. Based on the findings of this study, it can be hypothesized that the elementary learners had less knowledge of conceptual awareness than the intermediate learners and consequently made more conceptual errors.

The results of this study demonstrated conceptual errors in the category of parity outnumbered those in the internal content category at both levels. This outcome, on the one hand, may evidence that the process of conceptual translation played a more leading role in the category of parity. On the other hand, it backs up Pavlenko's (2009) proposition of conceptual non-equivalence which seems to correspond to Jarvis' (2007) category of parity. Defining it as a linguistic category of one language that does not have a counterpart in another language, Pavlenko states that some bilinguals may pause, hesitate and stutter to search for a nonexistent translation while coming across conceptual non-equivalence. She contends that non-equivalence complicates learning since learners have to develop new categories, and that it is more challenging in the case of abstract or emotion categories.

As for the role of age in conceptual transfer in this study, the younger elementary learners were more susceptible to conceptual transfer than their older counterparts. This finding runs counter to the general belief regarding age in language transfer that "child learners are less likely to draw on their L1, particularly in a pervasive way that leads to fossilization, than are adult learners" (Murphy, 2003, p. 11). Meanwhile, this negative relationship between conceptual transfer and age in this study muddies the waters of the principle that 'the younger is better' at least in terms of conceptual transfer. Also, among the findings of this study was the result that age difference in the intermediate learners, unlike that in the elementary learners, did not have a remarkable effect on their conceptual transfer suggesting that the more language proficiency the less effect of age in conceptual transfer. Apparently in this study, the intermediate learners had gained more conceptual awareness, hence better able to figure out that their native language concepts cannot always have exact word for word equivalence in English or that there are sometimes some layers of conceptual nuances in the two languages.

Not unrelated to the mentioned-above relationship between language proficiency and age in conceptual transfer is the correspondence between cognitive maturity and age. In language comprehension, L2 users' level of cognitive maturity affects their ability to comprehend the concepts expressed through language (Weist, 2002), and to abstract important conceptual, lexicosemantic, and morphosyntactic information from the new words they encounter (e.g., Weinert, 2004). Correspondingly, cognitive maturity may be deemed as a factor which explains why the youngest elementary learners in this study committed the most conceptual errors among the other participants.

\section{Further Research Areas}

The following can be suggested for further investigations:

1. Future research can investigate into other two categories of Jarvis' (2007) framework such as internal structure and external membership.

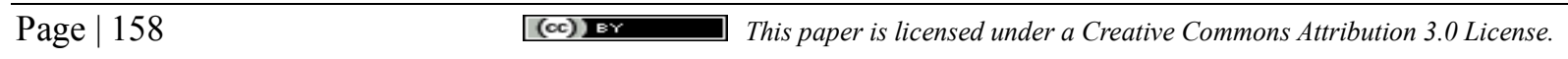


International Journal of Applied Linguistics \& English Literature

ISSN 2200-3592 (Print), ISSN 2200-3452 (Online)

Vol. 1 No. 4; September 2012

2. Further investigations into conceptual transfer can be conducted at advanced levels to find out about the possibility and extent of conceptual errors.

3. Future studies can test the role of other learner-base and language-based variables in conceptual transfer.

4. Next studies can also examine the ways and techniques through which FL textbook authors and teachers would help learners understand the subtle differences between concepts of native and foreign languages.

\section{Implications of the Study}

Learning a new language involves learning to conceptualize the world in a different way, from new ways of categorizing objects, events, and phenomena to making new attributions to familiar objects and events (Jarvis and Pavlenko, 2008). The findings of this study showed that EFL learners had difficulty in developing L2 conceptual internalization seemingly due to the influence of their native language on L2. Pedagogically speaking, input and context for FL learners, as Kecskes and Papp (2000) noted, do not go beyond word definition to form a multimodal representation and form a concept. On the other hand, concept internalization is obviously a long and arduous process. Thus, textbook authors and teachers should be concerned with finding ways to present multiple opportunities to face conceptually difficult issues and areas, in different formats, throughout the years of instruction in order to raise awareness of negative conceptual transfer through cross linguistic comparisons. For example, learners can take part in communicative practices that help them to attend to new conceptual distinctions. Such experiences could involve miscommunications that serve to highlight cross linguistic differences in the representation of particular concepts.

Based on the findings of this study, raising conceptual awareness had better commence at the elementary level and considerable attention needs to be paid to the concepts fallen into the category of parity.

\section{References}

Danesi, M. (2008). Conceptual errors in second language learning. In De Knop, Sabine De Rycker, Teun cognitive approaches to pedagogical grammar. (pp. 231-258)._Berlin, New York (Mouton de Gruyter).

Flege, J., \& MacKay, I. (2004). Perceiving vowels in a second language. Studies in Second Language Acquisition, vol. 26, pp. 1-34

Fowler, W.S. \& Coe, N. (1976). Nelson English Language Tests. Nelson ELT.

Ijaz, I.H. (1986). Linguistic and cognitive determinants of lexical acquisition in a second language. Language Learning, vol.36, pp. 401-451.

Jarvis, S. (1998). Conceptual transfer in the interlingual lexicon. Bloomington, IN: Indiana University Linguistics Club Publications.

Jarvis, S. (2002). Topic continuity in L2 English article use. Studies in Second Language Acquisition, vol. 24, pp. $387-418$.

Jarvis, S. (2007). Theoretical and methodological issues in the investigation of conceptual transfer. Vigo International Journal of Applied Linguistics, 4, 43-71.

Jarvis, S. (2010). Explorations in conceptual transfer. 10th Research Seminar in English Linguisti Circle. Facultade de Filoloxía. University of Santiago de Compostela. 22 January.

Jarvis, S. (2009). Conceptual Transfer Crosslinguistic Effects of Mental Concepts and Patterns of Conceptualization. Invited lecture presented at Zurich University of Applied Sciences in Winterthur (ZHAW). November 26.

Jarvis, S., \& Pavlenko, A. (2008). Crosslinguistic influence in language and cognition. London: Routledge. Jiang, N. (2000). Lexical representation and development in a second language. Applied Linguistics, 21, 47-77. Jiang, N. (2002). Form-meaning mapping in vocabulary acquisition in a second language. Studies in Second Language Acquisition, 24, 617-637.

Jiang, N. (2004). Semantic transfer and its implications for vocabulary teaching in a second language. The Modern Language Journal, 88, 416-432

Kasper, G. (1997). The role of pragmatics in language teacher education. In K. Bardovi-Harlig \& B. S. Hartford (Eds.), Beyond methods: Components of language teacher education (pp. 113-136). New York: McGraw-Hill.

Kecskes, I., \& Papp, T. (2000). Foreign language and mother tongue. Mahwah, NJ: Erlbaum.

Page | $159 \quad$ This paper is licensed under a Creative Commons Attribution 3.0 License.




\section{International Journal of Applied Linguistics \& English Literature \\ ISSN 2200-3592 (Print), ISSN 2200-3452 (Online) \\ Vol. 1 No. 4; September 2012}

Kroll, J. F., \& Potter, M. C. (1984). Recognizing words, pictures, and concepts: A comparison of lexical, object, and reality decisions. Journal of Verbal Learning and Verbal Behavior, vol. 23, pp. 39-66.

Lakoff, G. (1987). Women, fire, and dangerous things. What categories reveal about the mind. Chicago: University of Chicago Press

Levelt, W. (1989). Speaking: From intention to articulation. Cambridge, MA: MIT Press.

MacWhinney, B.(1992). Transfer and competition in second language learning. In R.J. Harris (Ed.) Cognitive processing in bilinguals. (pp. 371-390). Amsterdam: North Holland.

Matthews, S., \& Yip, V. (2003). Relative clauses in early bilingual development: Transfer and universals. In A. Giacalone Ramat (Ed.), Typology and second language acquisition (pp. 39-81). Berlin, Germany: Mouton de Gruyter

Murphy, S. (2003) Second language transfer during third language acquisition. In Working papers in TESOL en applied linguistics. Vol. $3 \mathrm{nr}$. 1. Retrieved June, 2010 from

http://journals.tc-library.org/index.php/tesol/search/titles?searchPage=3

Odlin, T. (1989). Language transfer: Cross-linguistic influence in language learning. Cambridge, UK:

Cambridge University Press.

Odlin, T. (2005). Cross-linguistic influence and conceptual transfer: What are the concepts? Annual Review of Applied Linguistics, 25: 3-25

Odlin, T. (2008). conceptual transfer and meaning extension, Terence Odlin, p. 306- 341. In Peter Robinson, Nick C. Ellis (2008). Handbook of cognitive linguistics and second language acquisition. Routledge: Taylor \& Francis Group

Pavlenko, A. (1998). SLA and acculturation: Conceptual transfer in L2 learners' narratives. Paper presented at AAAL 1998, Seattle, WA, March Rocher, A. (1993). "Creative betrayal: Anatomy of notional transfer in Asian cultures". TTR, vol.6, pp. 11-37.

Pavlenko, A. (2009) Conceptual representation in the bilingual lexicon and second language vocabulary learning. In Pavlenko, A. (ed.) The bilingual mental lexicon: Interdisciplinary approaches. Clevedon, UK: Multilingual Matters, pp. 125-160

Rocher, A. (1993). "Creative betrayal: Anatomy of notional transfer in Asian cultures”. TTR, vol.6, pp. 11-37.

Slobin, D. (1991). Learning to think for speaking: Native language, cognition, and rhetorical style. Pragmatics, vol.1 (7), PP. 25-71.

von Stutterheim, C., \& Klein, W. (1987). A concept-oriented approach to second language studies. In C. W. Pfaff (Ed.), First and second language acquisition processes(pp. 191- 205). Cambridge, MA: Newbury House.

Weinert, S. (2004). The acquisition of vocabulary and cognitive development. Sprache-Stimme-Gehor, vol.28, pp. 20-28.

Weist, R. (2002). Temporal and spatial concepts in child language: Conventional and configurational. Journal of Psycholinguistic Research, 31, 195-210.

$\mathrm{Yu}, \mathrm{M}$. (2004). Interlinguistic variation and similarity in second language speech act behavior. Modern Language Journal, vol. 88, pp. 102-119. 